\title{
MODELING THE GLOBAL ENGINEERING PROCESS IN AN AEROSPACE ORGANIZATION
}

\author{
Aurel Mihail Tîțu1,2, Gheorghe Ioan Pop ${ }^{3}$ \\ 1 "Lucian Blaga" University of Sibiu, 10, Victoriei Street, Sibiu, România \\ 2 The Academy of Romanian Scientists, 54, Splaiul Independenței, Sector 5, Bucharest, Romania \\ ${ }^{3}$ S.C. Universal Alloy Corporation Europe S.R.L. Dumbravita 244A, Maramures, Romania, \\ Emails: mihail.titu@ulbsibiu.ro,popghitza@gmail.com,
}

\begin{abstract}
The functioning of systems and processes within industrial organizations depends on a wide variety of factors and their interdependencies. The methods of modeling systems and processes depend on the perspective of those who want to analyze them. Systems, processes and activities can be modeled by all known methods, but they will be understood differently - depending on the point of view of those who approach them. The aim of the paper is to highlight how the engineering process in the industrial field occupies a large part of the cumulation of organizations' processes, constituting the processes that have the most developed knowledge of manufacturing processes. These processes are the "lever" of industrial organizations, due to the impact they have on the manufacture of products and their level of quality. Another aspect highlighted by this study is the integration of product requirements in manufacturing processes, which is achieved through engineering processes depending on the capabilities and capabilities of organizations. Manufacturing processes for metal structural components are classified according to the applied technology. Once the requirements and the necessary knowledge have been established, it is necessary to analyze the process and analyze the interaction of the requirements. To analyze an existing process, an x-ray of the process is required. In the last part of the research, the deliverables of this global engineering process were analyzed, and those deliverables generated based on product quality requirements and existing knowledge were identified - which have the greatest influence on the whole process.
\end{abstract}

Keywords: Global process of engineering, Systems, Modeling, Deliverables, Industrial organization.

\section{Introduction}

The engineering global process, represent the aggregation of all industrial organization processes responsible with manufacturing documentation preparation. These processes are those ones which manage product design documentation and convert to manufacturing documentation, inspection/ verification documentation. Also, in this group of processes can be found the processes which convert design data into technical data base having the purpose to support quality and commercial processes.

International standardization organizations have developed a quality management system in order to facilitate organizations access to a reference structure on how to organize processes. How to make a process map is a concrete example of a method that can be used to model the systems and processes of organizations.

However, the creation of the process map is done at a more general level, without highlighting the factors that influence the processes and the interaction between them [1], [2].

Thus, some aerospace industry organizations use other methods of visualizing the process from different perspectives [3]:

- Understanding sequences within processes or systems by making a flowchart that includes both processes and sequences within a process. This method helps to track process connections. It is a very useful method in managing nonconformities due to the fact that these diagrams go through the entire manufacturing process including quality control and engineering processes.

- Control the inputs and outputs of different sequences of one or more processes following the moments in the process in which the deliverables are created. This approach uses input-output diagrams and block sequences.

The engineering process, in an industrial organization in aerospace, is that process which is responsible for the transfer of product 
requirements into manufacturing requirements [4], [5].

The manufacturing process is the complementary process to the engineering process, a process that deals exclusively with the manufacture of products and their control [6], [7]

\section{Modeling of Engineering Systems and Processes in the Industrial Field}

Tracking the manufacturing time of some products through visual flow charts (VSM - Visual Stream Map). These diagrams are often used in aerospace, due to the fact that they allow customers to view all the steps necessary to manufacture products, from ordering the raw material to delivery to the customer, including time intervals allocated to logistics processes and waiting times (figure 1).
The methods of modeling systems and processes depend to a large extent on the perspective of those who want to analyze them [8], [9].

The same systems, processes and activities can be modeled by all known methods, but they will be understood differently - depending on the point of view of those who approach them.

The visual diagram of the manufacturing flow is used, within industrial organizations, in order to visualize the entire manufacturing process of the product from the perspective of the manufacturing cycle. The visualization of internal and external processes allows industrial organizations to easily manage any improvement [10], [11]. Also, manufacturing and logistics times help in calculating product costs.

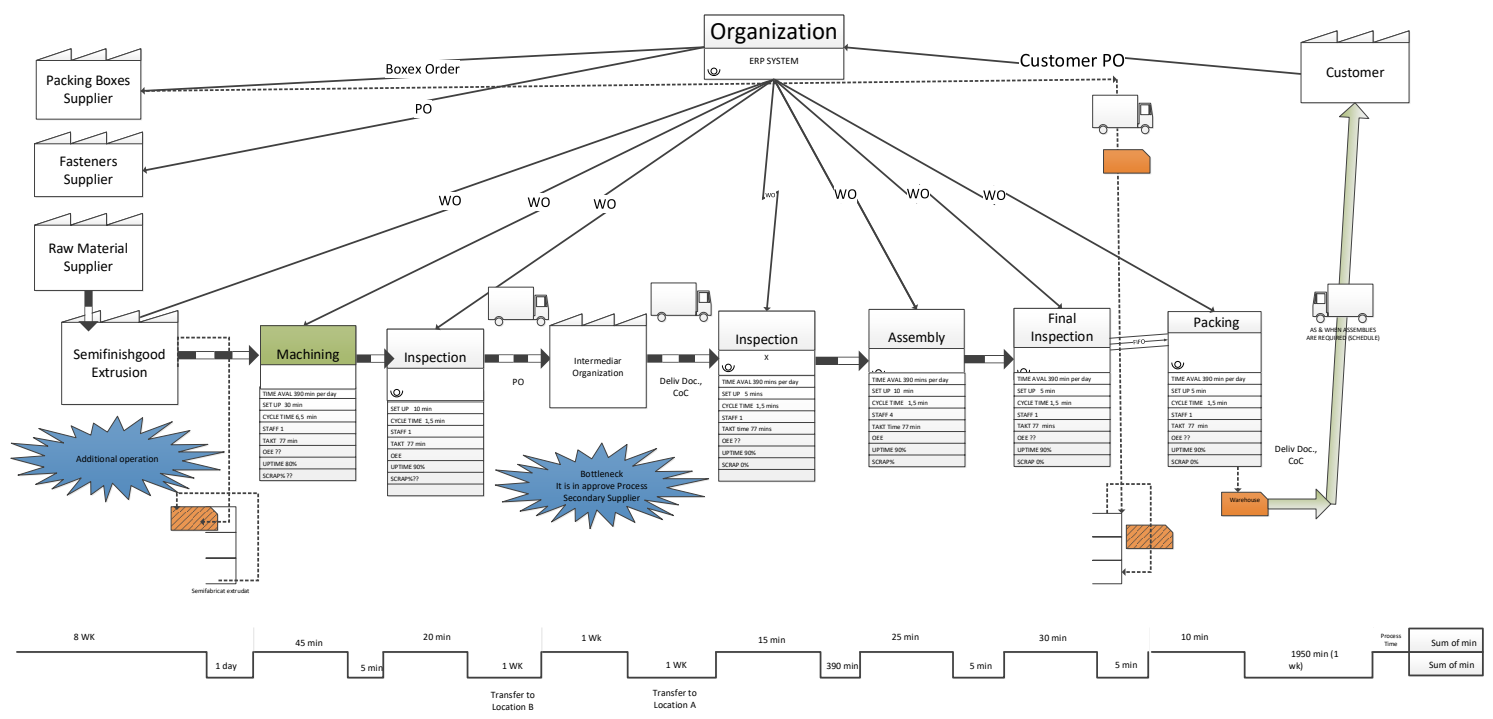

Figure 1: Visual Stream Map of aerospace structural product

The industrial engineering process occupies a large part of the cumulation of organizations' processes, constituting the processes with the most developed knowledge of manufacturing processes [12], [13]. These processes are the "lever" of industrial organizations, due to the impact they have on the manufacture of products and their level of quality [14], [15]. Manufacturing and engineering processes, in manufacturing organizations, work only together and the capabilities of each type of process, individually, affect the other [16]. The capability of an engineering process in an industrial organization can be quantified by the level of technical knowledge it has at a given time through the available resources. The capability of manufacturing processes is given by the level of technology in an industrial organization. As can be seen in Figure 2, engineering processes can only be applied if there are manufacturing processes with technology and technological equipment capable of taking over the "engineering" generated by the engineering processes.

High-capacity manufacturing processes cannot be valued if the level of technical, mathematical knowledge and applied logical thinking are not present.

Industrial engineering processes can be represented by:

- Product design processes;

- Execution documentation processes:

- The processes of configuring the technical data management systems;

- Technological process design processes;

- Quality engineering processes.

Design processes - occupy the most important place in engineering processes, due to their main purpose - to use technical knowledge and not 
only for the development of products required by customers.

These processes are found in organizations dedicated to product design but are largely found in manufacturing organizations. Their purpose is to design the technology needed to manufacture the products. This area includes the design of devices necessary for technological equipment, devices that ensure the connection between the technological equipment and the product being made.
The manufacturing documentation processes are based on the conversion of the product documentation as designed, into documentation specific to the manufacturing organizations. These processes are specific to the manufacturing organization, being developed within them, most often, depending on the requirements of the manufacturing processes.

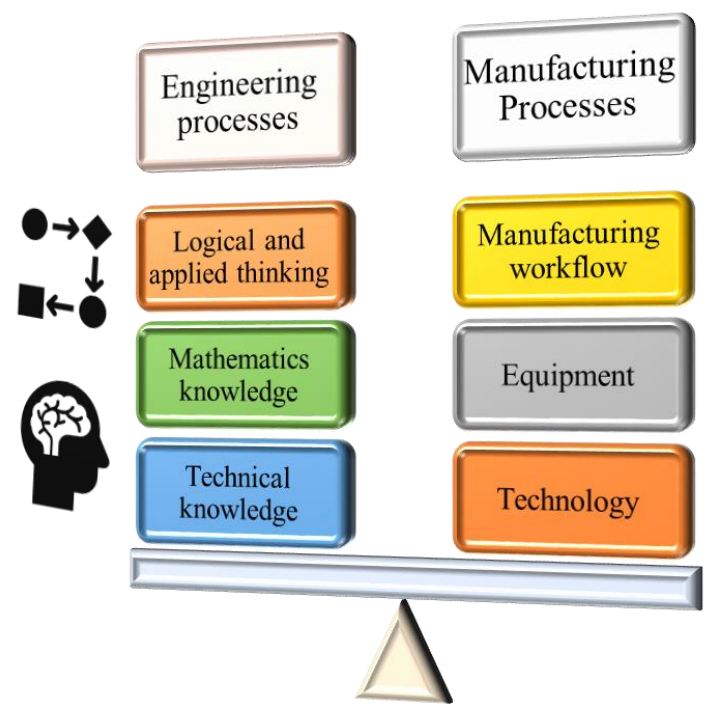

Figure 2: Correlation of engineering processes with manufacturing ones

The manufacturing documentation can be considered as:

- Technical execution drawings derived from those designed;

- Visual aids on the shape and dimensions of the products;

- Files for installing/uninstalling devices and products along the technological route;

- Programs for coordinate processing machines, equipment for thermal processes, plastic deformation processes, painting processes, etc.

The processes of configuring the technical data management systems, represent those processes that establish and control the flow of technical data of the products, necessary for the manufacturing processes.

In aerospace, a special emphasis is placed on the management of the technical data of the products. These are necessary for the manufacturing and qualification processes, respectively the certification of each individual product. Therefore, the methods of configuring technical data are supported by dedicated electronic control systems, such as: ERP (Enterprise Resource Planning) applications, PLM (Product Lifecycle Management), PLM (Product Lifecycle Management), PDM (Product Data
Management), DMS (Document Management System). All these applications have been developed by various organizations in order to help manufacturing organizations to minimize manual activities. However, the aerospace configuration product data is performed by each organization on the specifics of their activities using only as tools these applications.

Technological process design processes are those processes that convert projected product and process requirements into technological flow requirements.

As can be seen in Figure 3, in the industrial field, the design process of the technological manufacturing process, uses, in addition to product requirements and manufacturing process requirements. In aerospace, in addition to the process requirements defined in international standards, those defined by large manufacturers are taken into account for the design of the process and the interleaving of specific inspection operations.

One of the most important aspects in the design of the technological process is that of knowing the capability of the processes within the organization.

The processes of designing technological processes in industrial organizations in aerospace 
with specificity in the manufacture of structural components include the processes of designing the strategy of processing and cold or hot plastic deformation of products, but also the processes of surface treatment and assembly.

The more the manufacturing process within an organization comprises several stages of the product manufacturing process, the more complex and difficult the process of designing the technological process.

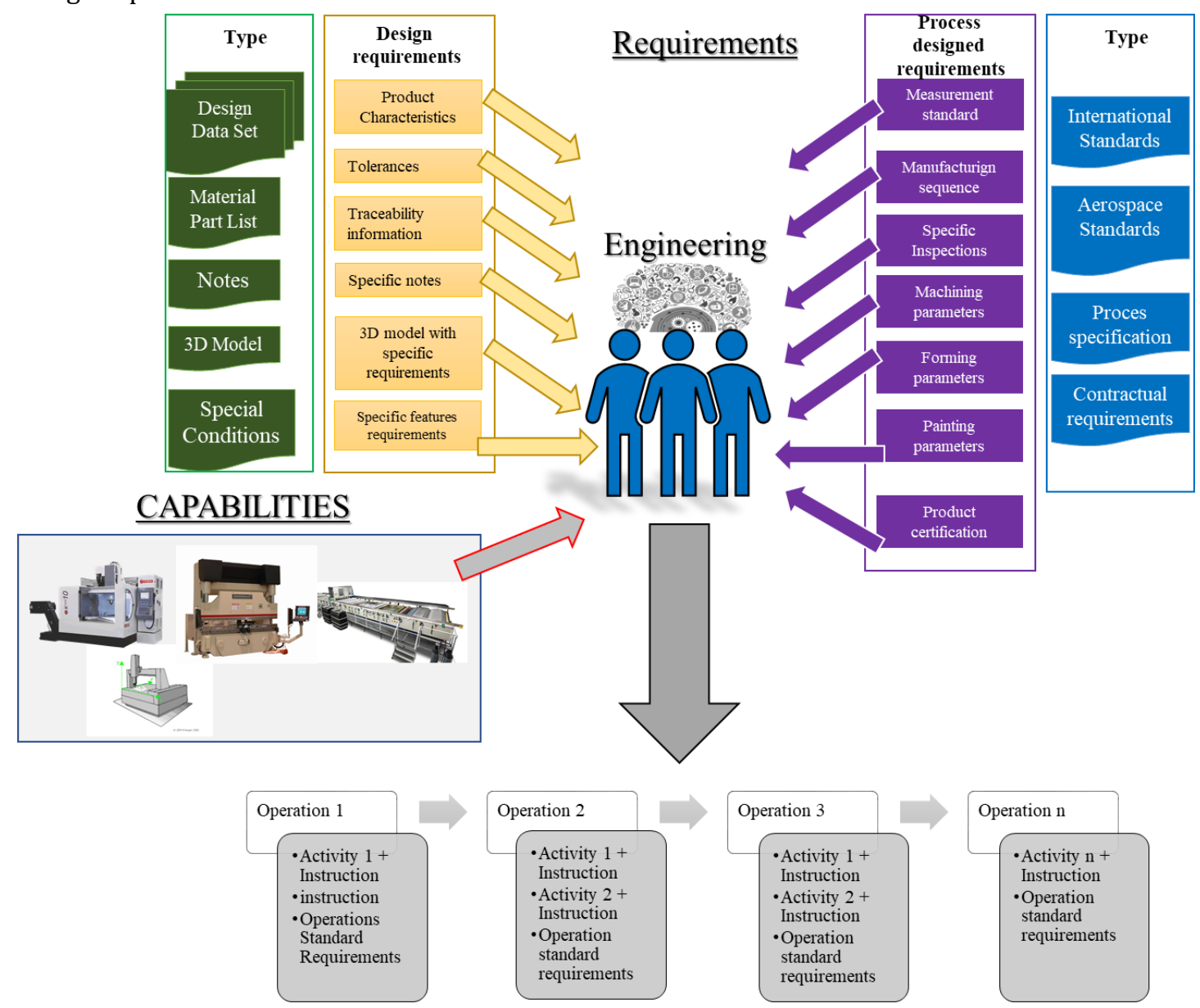

Figure 3: The flow of requirements and their conversion into a technological manufacturing process

\begin{tabular}{|c|c|c|c|c|c|c|c|c|c|c|c|}
\hline $\begin{array}{l}\text { Manufacturing } \\
\text { Workflow }\end{array}$ & Material & Logistics & $\begin{array}{l}\text { Mechanical } \\
\text { Operation }\end{array}$ & Logistics & $\begin{array}{c}\text { Surface } \\
\text { Protection } \\
\text { Operations }\end{array}$ & Logistics & $\begin{array}{l}\text { Assembly } \\
\text { Operation }\end{array}$ & Logistics & $\begin{array}{c}\text { Custome } \\
\mathbf{r}\end{array}$ & Description & $\begin{array}{c}\text { Total cost } \\
\text { reduction } \\
{[\%]}\end{array}$ \\
\hline Version 1 & $40 \%$ & $4 \%$ & $20 \%$ & $4 \%$ & $8 \%$ & $4 \%$ & $16 \%$ & $4 \%$ & & \multirow{2}{*}{$\begin{array}{c}\text { Manufacturing } \\
\text { cost } \\
\text { distribution } \\
\end{array}$} & \multirow[b]{2}{*}{$0 \%$} \\
\hline $\begin{array}{c}\text { Manufacturing } \\
\text { Process }\end{array}$ & $\begin{array}{l}\text { Organization } 1 \\
\text { Manufacturing } \\
\end{array}$ & & $\begin{array}{l}\text { Organization } 2 \\
\text { Manufacturing } \\
\end{array}$ & & $\begin{array}{l}\text { Organization } 3 \\
\text { Manufacturing } \\
\end{array}$ & & $\begin{array}{l}\text { Organization } 4 \\
\text { Manufacturing } \\
\end{array}$ & & Customer & & \\
\hline Version 1 & $40 \%$ & $4 \%$ & $20 \%$ & $0 \%$ & $8 \%$ & $0 \%$ & $16 \%$ & $4 \%$ & & \multirow{2}{*}{$\begin{array}{c}\text { Manufacturing } \\
\text { cost } \\
\text { distribution } \\
\end{array}$} & \multirow[b]{2}{*}{$8 \%$} \\
\hline $\begin{array}{l}\text { Manufacturing } \\
\text { Process }\end{array}$ & $\begin{array}{l}\text { Organization } 1 \\
\text { Manufacturing }\end{array}$ & & $\begin{array}{l}\text { Organization } 2 \\
\text { Manufacturing }\end{array}$ & & $\begin{array}{l}\text { Organization } 2 \\
\text { Manufacturing } \\
\end{array}$ & & $\begin{array}{l}\text { Organization } 2 \\
\text { Manufacturing }\end{array}$ & & Customer & & \\
\hline
\end{tabular}

Figure 4: Comparison of two manufacturing processes in relation to the cost of the product

An essential role in the process of designing the technological process is also played by the knowledge of engineers on the entire manufacturing process specific to structural components. This aspect is also valid when the capabilities of the organization are limited,
On the other hand, from the point of view of the cost of the products, it is preferable for the whole technological process to take place within the same organization. A concrete example can be seen in Figure 4, where once the logistics operations are eliminated, a cost reduction of about $8 \%$ can be obtained. 
process control. The method of product control in aerospace manufacturing organizations is that which creates a product control plan in relation to technological operations, where all product requirements, both product and process, are defined (Figure 5).

Due to the fact that this process collects and centralizes all product requirements, it is located at the end of the global engineering process. This process, in addition to the process and product requirements, must also incorporate a response plan in the control plan if the measured values tend to exceed the control limits (tolerances). Some of the requirements also appear from the manufacturing processes, after the first batches manufactured, as preventive actions to control the processes.

Controlplan

$\square$ Prototype $\square$ First Release $\square$ Serial Production

\begin{tabular}{|c|c|c|c|c|c|c|c|c|c|c|c|}
\hline \multicolumn{4}{|c|}{ Control Plan Number } & \multicolumn{5}{|c|}{ Supplier Contact } & Date (initial): & \multicolumn{2}{|c|}{ Revision Date: } \\
\hline \multicolumn{4}{|c|}{ Product Number / last revision } & \multicolumn{5}{|c|}{ Base team } & \multicolumn{3}{|l|}{ Customer engineering approval date (FA) } \\
\hline \multicolumn{4}{|c|}{ Product Description } & \multicolumn{5}{|c|}{ Supplier location/Approval Date } & \multicolumn{3}{|l|}{ Customer quality approval date (FA) } \\
\hline \multicolumn{2}{|c|}{ Supplier Location } & \multicolumn{2}{|c|}{ Supplier Code } & \multicolumn{5}{|c|}{ Customer / Approval Date } & \multicolumn{3}{|l|}{ Other approval (IFA) } \\
\hline \multirow[b]{2}{*}{$\begin{array}{l}\text { Process } \\
\text { Number }\end{array}$} & \multirow[b]{2}{*}{$\begin{array}{c}\text { Process } \\
\text { description }\end{array}$} & \multirow[b]{2}{*}{ Equipment } & \multicolumn{3}{|c|}{ Characteristics } & \multirow[b]{2}{*}{$\begin{array}{c}\text { Special } \\
\text { Characteristic }\end{array}$} & \multicolumn{3}{|c|}{ Method } & & \\
\hline & & & Number & Product & Process & & $\begin{array}{l}\text { Product/process } \\
\text { spec./tolerance }\end{array}$ & $\begin{array}{l}\text { Evaluation/ } \\
\text { Measurement }\end{array}$ & Sample & $\begin{array}{l}\text { Control } \\
\text { Method }\end{array}$ & $\begin{array}{c}\text { Reaction } \\
\text { Plan } \\
\end{array}$ \\
\hline
\end{tabular}

Figure 5: Example of the content of a control plan for structural products in the aerospace

\section{Methods for Integrating Product Requirements}

The integration of product requirements in manufacturing processes is achieved through engineering processes depending on the capabilities of organizations in aerospace.
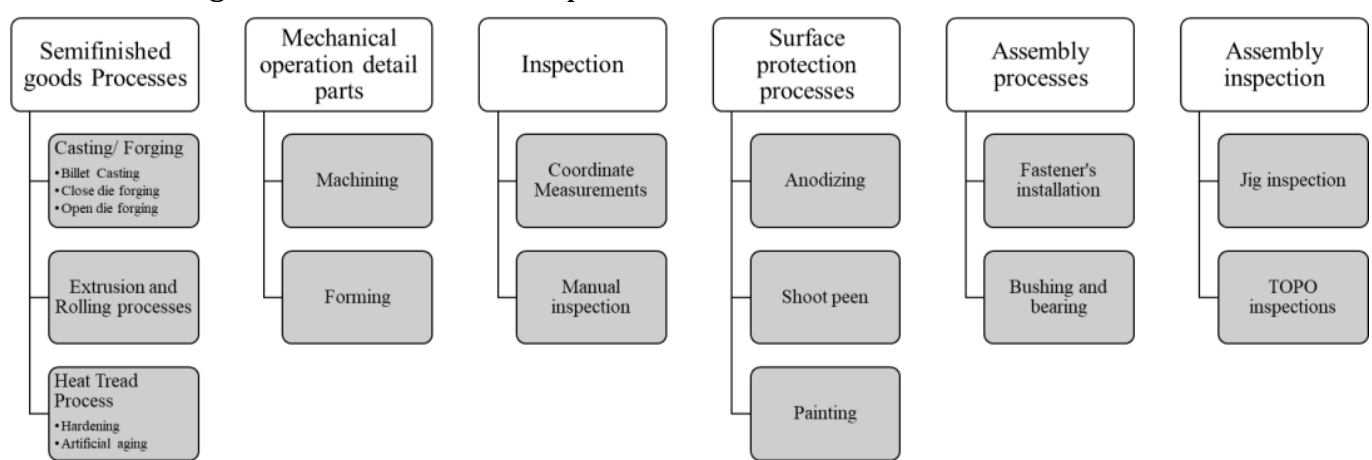

Figure 6: Categories of manufacturing processes for mechanical structural products in aerospace

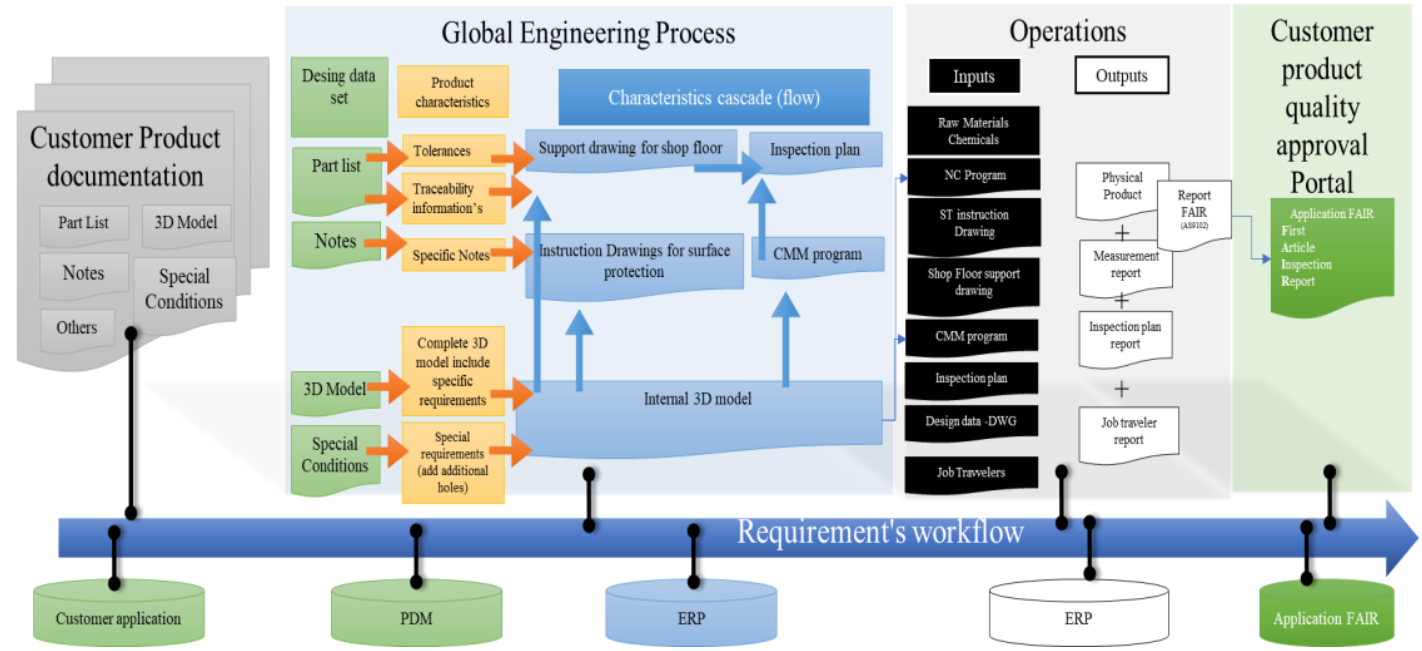

Figure 7: Example method applied in industrial organizations for the integration of structural product requirements, requirements defined on the basis of $3 D$ models without execution drawings 
The integration method is based on the central engineering system of the organization, which after receiving the documentation from customers, makes available to all processes, respectively to the entire organization, the requirements of the products configured in a database. This database generally targets all organizations in the field and is integrated into an ERP application designed for this purpose.
The database contains some of these requirements. Certain requirements do not need to be converted in the form of data, due to the fact that they are used in the designed form. Execution or assembly drawings and 3D models as well as designed technical documentation of the product - contain clearly expressed requirements and are used in the same form in manufacturing processes.

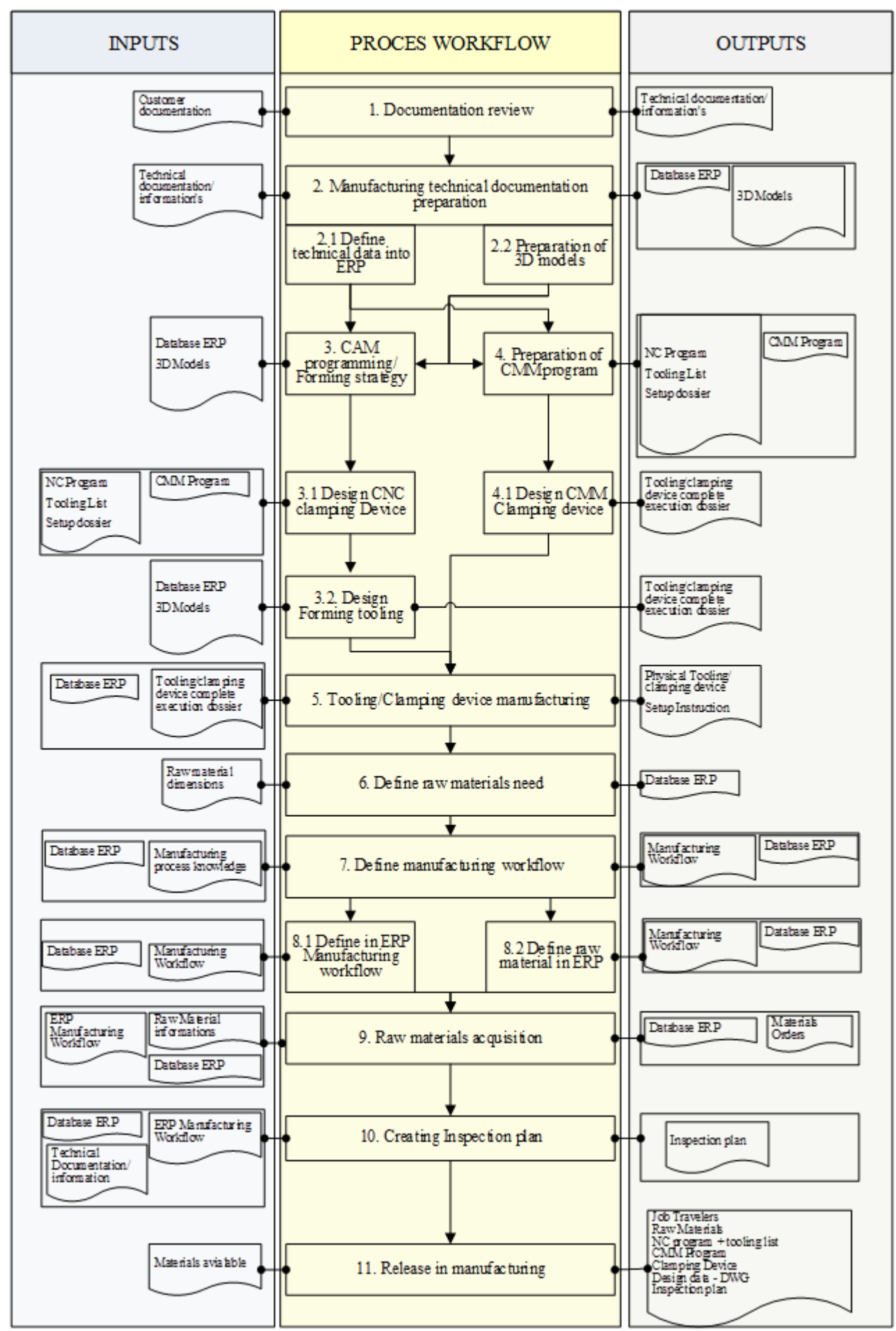

Figure 8: The flow of the global engineering process in aerospace industrial organization that processes metal structural components 
Figure 7 shows visually a method of integrating the requirements in the manufacturing processes and those of certification / validation of some metal structural products, through the global engineering process. The integration of requirements is possible due to IT systems and the connections between them, which facilitates access to the same requirements in both engineering and production processes.

The requirements for structural products in aerospace consist of:

- Execution drawings of parts;

- Designs or standards of standardized semifinished products;

- Lists of materials containing the requirements:

o Numbers of standard drawings or material standards;

o Dimensions of semi-finished products, where there are no standardized drawings; o Information in the form of codes required for surface treatments;

o Code information on the safety class or functionality of the product in aircraft, used in establishing special inspection criteria.

- Documentation approval lists from the point of view of:

o Product design;

o Structural analyzes (static, dynamic and fatigue);

o Design of aircraft operation.

- Special requirements for the delivery of products in addition to those designed or for the modification of certain requirements designed in order to facilitate assembly processes;

- Contractual requirements;

- Technological process requirements applicable to various product categories.

All these requirements are used in the overall engineering process in various component processes, depending on their purpose.

The designed technical documentation and the execution documentation is integrated in the ERP system so that it can be accessed and used in the production processes.

Once all the documentation is integrated and completed, the technological sheets of the products are generated and distributed in the manufacturing processes together with the manufacturing documentation for the realization of the products ordered by the customers.

Following the realization of the manufacturing and inspection processes, in addition to the physically made product, in the process of product validation, measurement sheets and inspection plans are generated. They are subsequently used in the product certification documentation, as can be seen in Figure 7, last block.

This method is one of integrating requirements into manufacturing processes, generally applicable in manufacturing organizations, in all fields.

The specificity of this method is given by the way of centralized use of the product requirements, from the receipt of the technical documentation to the certification, respectively the delivery of the product.

Figure 8 shows the same process, but from a different perspective - from that of integration into the quality management system.

This whole integration process is ensured by working procedures and instructions that describe the applicable activities in a more detailed or general form.

These procedures and instructions ensure compliance of the process with the standard of the aerospace quality management system AS9100: 2016.Following the study of process analysis methods and their integration, we came to the conclusion that the IDEFO methodology can be applied most easily and can identify process interruptions - which are currently solved by point solutions and not by system solutions.

\section{Conclusions}

Once the requirements and the necessary knowledge have been established, it is necessary to analyze the process and analyze the interaction of the requirements.

To analyze an existing process, an x-ray of the process is required. By analyzing the deliverables of this global engineering process, one can identify those deliverables generated based on product quality requirements and existing knowledge - which have the greatest influence on the entire process.

The deliverables that we have identified as the most frequently used as inputs for the whole process, are represented by the database of the ERP system and the virtual model of the product the 3D model. This result is generated by the integration of existing processes through the use of an ERP system for product data management and manufacturing processes as well as the use of CAD / CAM / CMM methods. Industrial organizations in aerospace field and not only, use various methods of process analysis, depending on the purpose they have with this analysis. Regardless of the method used, the analyst aims to identify:

- Name of the process;

- Sequences within the process;

- Process deliverables. 
In addition, the inputs and outputs of each process, the interaction with external processes, the time required to go through the process, the checkpoints in the process and the decisionmaking areas within the process can also be tracked.

The analysis of the requirements on how they are integrated in the manufacturing processes, allow industrial organizations to identify alternative variants of technological manufacturing routes of products, in order to reduce risks, costs and manufacturing cycle.

Following the path that product quality requirements have from the customer, the process of engineering, production, product verification and certification, customer approval, perspective on requirements management and their influence on product quality allows a very clear analysis of the influences and opportunities for improvement.

The development of the matrix of structural product quality requirements in the aerospace field, so that it can be used in the process of validating product requirements in the process of preparing inspection plans necessary for the industrial manufacturing process, is a research direction.

Likewise, the development of the global requirements analysis model, so as to allow industrial organizations to use this model prior to the manufacturing process, from the product bidding phase for the estimated calculation of product manufacturing costs is an additional research direction.

\section{References}

[1] Masten, Scott E; The Organization of Production: Evidence from the Aerospace Industry." Journal of Law \& Economics 27, no. 2: 403-17, Published: 1984.

[2] Boyer, R.R.; An overview on the use of titanium in the aerospace industry, Materials Science and Engineering: A, Volume 213, Issues 1-2, Pages 103-114, Published: 1996.

[3] Rebolledo, C.; Nollet, J.; Learning from suppliers in the aerospace industry, International Journal of Production Economics, Volume 129, Issue 2, Pages 328337, Published: 2011.

[4] Wu, TH.; Wu, F.; Liang, CJ.; A virtual reality tool for training in global engineering collaboration. Univ Access Inf Soc 18, 243255, Published: 2019.

[5] Rojo Abollado, J.; Shehab, E.; Bamforth, P.; Challenges and Benefits of Digital Workflow Implementation in Aerospace Manufacturing Engineering, Procedia CIRP, Volume 60, Pages 80-85, Published: 2017.

[6] Alblawi, A.; Nawab, M.; Alsyaari, A.; Application of systems engineering approach in senior design projects," 2018 IEEE Global Engineering Education Conference (EDUCON), pp. 1151-1160, Published: 2018.

[7] Queiruga-Dios A.; et al.; Evaluating engineering competencies: A new paradigm," 2018 IEEE Global Engineering Education Conference (EDUCON), pp. 2052-2055, Published: 2018.

[8] Shimin, L.; Jinsong, B.; Yuqian, L.; Jie, L.; Shanyu L.; Xuemin S.; Digital twin modeling method based on biomimicry for machining aerospace components, Journal of Manufacturing Systems, Volume 58, Part B, Pages 180-195, Published: 2021.

[9] Li, W.; Zhao, C.; Gao, F.; Linearity Evaluation and Variable Subset Partition Based Hierarchical Process Modeling and Monitoring," in IEEE Transactions on Industrial Electronics, vol. 65, no. 3, pp. 26832692, Published: March 2018.

[10] Jinlin, Z.; Zhiqiang, G.; Zhihuan, S.; Furong, G.; Review and big data perspectives on robust data mining approaches for industrial process modeling with outliers and missing data, Annual Reviews in Control, Volume 46, Pages 107-133, Published: 2018.

[11] Kazemzadeh, A.; Manteghi, M.; Tolouee Ashlaghi, A.; Jodey, J.; Identification and Modeling of Effective factors in Designing the Process of Developing Aerospace ComplexProducts. Innovation Management Journal, 9(3), 37-77, Published: 2020.

[12] Kassotaki, 0.; Explaining ambidextrous leadership in the aerospace and defense organizations, European Management Journal, Volume 37, Issue 5, Pages 552-563, Published: 2019.

[13] N'Cho, J.; Contribution of talent analytics in change management within project management organizations The case of the French aerospace sector, Procedia Computer Science, Volume 121, Pages 625-629, Published: 2017.

[14] Arpentieva, M.; Duvalina, O.; Gorelova, I.; Intersubjective management in aerospace engineering, MATEC Web Conf., 102 01002, Published: 2017.

[15] Kovrigin, E.; Vasiliev, V.; Trends in the development of a digital quality management system in the aerospace industry, IOP Conference Series: Materials Science and Engineering, Volume 868, 18th International Conference "Aviation and Cosmonautics", Moscow, Russian Federation, Published: 2020.

[16] Rajamani, M.; Punna, E.; Enhancement of Design for Manufacturing and Assembly Guidelines for Effective Application in Aerospace Part and Process Design," SAE Technical Paper 2020-01-6001, Published: 2020. 
